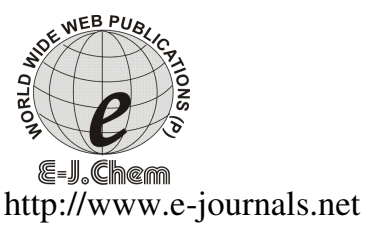

\title{
Estimation of Some Antiviral Drugs Using Tpooo as Analytical Reagent
}

\author{
P. VENKATA REDDY and B. SUDHA RANI* \\ University College of Pharmaceutical Sciences, \\ Andhra University, \\ Visakhapatnam -530003, (A.P.), INDIA.
}

Received 7 March 2006; Accepted 5 May 2006.

\begin{abstract}
A simple and reproducible spectrophotometric method has been developed for the determination of two recent antiviral drugs namely Valacyclovir (drug A) and Famciclovir (drug B) in bulk and pharmaceutical dosage forms. The method is based on the extraction of the drugs into organic layer of the dye TPooo in presence of $0.1 \mathrm{~N}$ hydrochloric acid and the absorbances were measured at 490 $\mathrm{nm}$. The method was optimized using eight parameters.
\end{abstract}

Keywords: Anti virals, Spectrophotometric determination, TPooo.

\section{Introduction}

TPooo, benzene sulfonic acid is chemically named as 4 [(4-hydroxy-1-napathalenyl azo]mono sodium salt. It is an azo dye. It is used for the estimation of antiviral drugs. Famciclovir, an orally available nucleoside analog with potent in vitro activity against HIV, is being investigated for treatment of chronic hepatitis B. Famciclovir induced rapid, dose-dependent suppression of viral replication and reduction in alanine aminotransferase (ALT), with greatest efficacy in the 500-mg tid treatment group. Valacyclovir is the prodrug of acyclovir and its activity is due to its conversion to acyclovir. A critical step in its activation is phosphorylation by viral thymidine kinase. The phosphorylation product acyclovir triphosphate (acyclo-GT P) terminates the production of viral DNA by inhibiting DNA polymerase via competition with deoxyguanosine triphosphate.It has selective affinity for viral DNA polymerase. Literature survey revealed the dissolution studies ${ }^{1-3}$, pharmacological data ${ }^{4-5}$ and high performance liquid chromatographic determination of antivirals using UV detection and mass 
spectrometry ${ }^{6-9}$. The authors proposed a simple and reproducible spectrophotometric method for the determination of antiviral drugs.

\section{Experimental}

Spectral and absorbance measurements were made on a Systronics UV-Vis Spectrophotometer (Model 117) with $10 \mathrm{~mm}$-matched quartz cells. All the chemicals used were of AR grade. Solutions of $0.2 \%$ TPooo and $0.1 \mathrm{~N}$ hydrochloric acid were prepared using distilled water. AR grade chloroform was used.

\section{Preparation of Standard solution:}

$100 \mathrm{mg}$ of FCV and $100 \mathrm{mg}$ of Valacyclovir were accurately weighed and dissolved in 100 $\mathrm{ml}$ of double distilled water to get a concentration of $1 \mathrm{mg} / \mathrm{ml}$. The stock solutions were suitably diluted to get a concentration of $100 \mu \mathrm{g} / \mathrm{ml}$.

\section{Preparation of sample solution:}

Two commercial brands of tablets namely Famtrex (cipla), Virovir (FDC) and Valcivir 500 and $1000 \mathrm{mg}$ (Cipla) were chosen for each drug. For this, tablets were weighed and powdered. An accurately weighed portion of this powder equivalent to $50 \mathrm{mg}$ of Famciclovir and $50 \mathrm{mg}$ of Valacyclovir was transferred to a $50 \mathrm{ml}$ volumetric flasks containing $25 \mathrm{ml}$ methanol. The contents were allowed to stand for $1 / 2 \mathrm{~h}$ with intermittent sonication to ensure complete solubility of the drug and then filtered through $0.45 \mu \mathrm{m}$ membrane filter. The volume was made to the mark with methanol. The solution is suitably diluted with methanol to get $100 \mu \mathrm{g} / \mathrm{ml}$.

\section{Preparation of the reagents}

Tpooo (0.2\%): Prepared by dissolving $200 \mathrm{mg}$ of Tropaeolin ooo in $100 \mathrm{ml}$ of distilled water.

$\mathrm{HCl}$ solution: prepared by dissolving $8.6 \mathrm{ml}$ of con $\mathrm{HCl}$ to $1000 \mathrm{ml}$ of distilled water and Standardized.

\section{Method}

Into a series of $125 \mathrm{ml}$ separating funnels containing aliquots of standard drug solution (0.5$2.5 \mathrm{ml}$ ) and $6.0 \mathrm{ml}$ of $\mathrm{HCl}$ solution and $2 \mathrm{ml}$ of dye solution were added. The total volume of aqueous phase in each separating funnel was adjusted to $15 \mathrm{ml}$ with distilled water and 10 $\mathrm{ml}$ of chloroform was added. The contents were shaken for 2 min. the two phases were allowed to separate and the absorbances of the separated organic layer were measured at 490 nm against a reagent blank prepared under identical conditions.

\section{Results and Discussion}

The optical characteristics such as Beer's law limits, Sandell's sensitivity, molar extinction coefficient, percent relative standard deviation and percent range of error were calculated (Figure 1-3) for the method and the results are summarized in Table 1. The accuracy of the methods was ascertained by comparing the results of the proposed methods with that of reported method (Table 2). In order to justify the reliability and suitability of proposed methods, known amounts of pure drug was added to its various pre analyzed dosage forms and were analyzed by the proposed method. The results 
presented in Table 3, which indicates that the proposed method can be successfully applied for the analysis of Famciclovir and Valacyclovir in dosage forms. The additives and excipients usually present in pharmaceutical preparations did not interfere.

Thus the proposed method was simple, sensitive, accurate and reproducible and can be used for the routine analysis of Famciclovir and Valacyclovir in bulk and in pharmaceutical dosage forms.

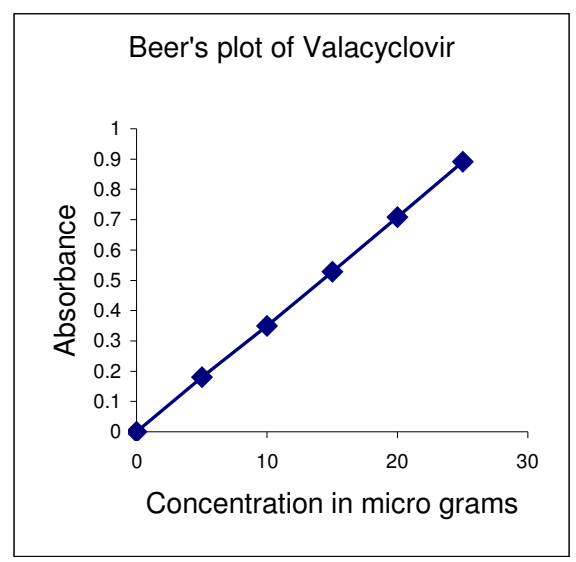

Figure 1

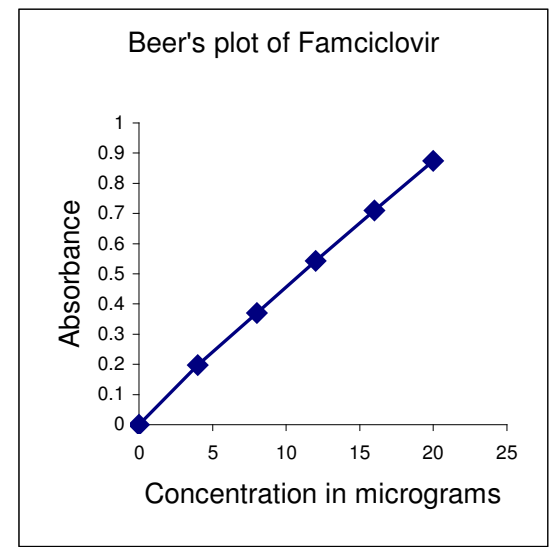

Figure 2

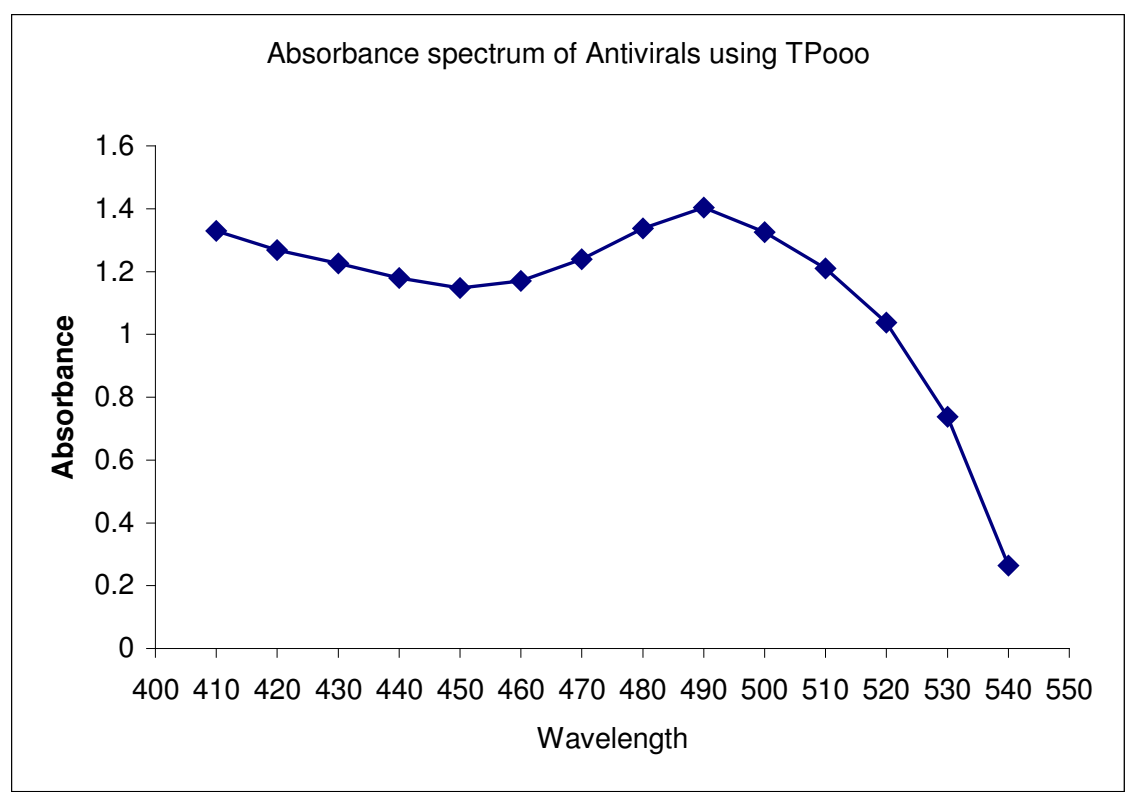

Figure 3 
Table 1. Optical Characteristics of the Proposed Method

\begin{tabular}{lll}
\hline Parameters & Famciclovir & Valacyclovir \\
\hline Beer's law limits $(\mu \mathrm{g})$ & $1-30 \mu \mathrm{g}$ & $1-20 \mu \mathrm{g}$ \\
Sandell's sensitivity & 0.0243 & 0.0120 \\
$(\mu \mathrm{g} / \mathrm{cm} 2 / 0.001$ absorbance unit) & & \\
Molar absorbtivity & 31590 & 30596 \\
\% Relative standard deviation & 0.2759 & 0.3440 \\
\% Range of error & & \\
0.05 confidence limits & 0.230 & 0.2920 \\
$\quad 0.01$ confidence limit & 0.341 & 0.4320 \\
Correlation coefficient & 0.9995 & 0.9998 \\
Regression equation $(\mathbf{Y}=\mathbf{b}+\mathbf{a c}) *$ & $\mathrm{Y}=0.043(\mathrm{C})+0.014$ & $\mathrm{Y}=0.0778(\mathrm{C})+0.0741$ \\
$\quad$ Slope (a) & 0.043 & 0.0778 \\
Intercept (b) & 0.014 & 0.0741 \\
\hline
\end{tabular}

$*$ Where $\mathrm{C}$ is the concentration in $\mu \mathrm{g} / \mathrm{ml}$ and $\mathrm{Y}$ is absorbance unit.

Table 2. Assay of Famciclovir and Valacyclovir in Pharmaceutical Formulations

\begin{tabular}{lcccc}
\hline Sample & $\begin{array}{c}\text { Labeled } \\
\text { amount }(\mathrm{mg})\end{array}$ & \multicolumn{2}{c}{$\begin{array}{c}\text { Amount obtained }(\mathrm{mg}) \\
\text { reference method* }\end{array}$} & $\begin{array}{c}\text { \% recovery by the } \\
\text { proposed method } \\
\text { proposed method }\end{array}$ \\
\hline 1. Famtrex & 250 & 250.8 & $252.6 \pm 0.44$ & $101.0 \pm 0.78$ \\
2. Virovir & 250 & 249.8 & $249.3 \pm 0.31$ & $99.72 \pm 0.13$ \\
3. Valcivir & 500 & 499.8 & $501 \pm 0.12$ & $100.2 \pm 0.21$ \\
\hline
\end{tabular}

*UV method developed by authors

Table 3. Recovery Studies of Famciclovir and Valcyclovir

\begin{tabular}{cccccc}
\hline Sample & $\begin{array}{l}\text { Amount } \\
\text { added } \\
(\mathrm{mg})\end{array}$ & $\begin{array}{c}\text { Amount recovered } \\
\text { by proposed methods } \\
(\mathrm{mg}) \\
\text { drug A }\end{array} \quad$ drug B & $\begin{array}{l}\text { Reference } \\
\text { method }\end{array}$ & $\begin{array}{l}\text { \% Recovery by the } \\
\text { proposed methods }\end{array}$ \\
\hline & & & drug A & drug B \\
\hline 1 & 100 & $99.36 \pm 0.34$ & $100.40 \pm 0.3$ & $99.41 \pm 0.51$ & $99.36 \pm 0.10100 .4 \pm 0.52$ \\
\hline
\end{tabular}

\section{References}

1. Hardman J G, Limbird L E, Eds. Goodman and Gilman's, The Pharmacological Basis of Therapeutics, $9^{\text {th }}$ ed,; The MC Graw Hill Co.; 1996.

2. Banakar, U.V.Pharmaceutical dissolution testing, $1^{\text {st }}$ Ed.; Marcel Dekker inc.; New York, 1992.

3. Rowe $\mathrm{S} \mathrm{R}$ and Carless $\mathrm{J}$ E,Comparison at the in vitro behavior of various Indomethacin formulations with their in vivo bioavailability. J.Pharm. Pharmacol.,1981, 33, 561-565.

4. Andrei, G; Eur J Clin Microbiol Infect Dis 1992, 11, 143 CA.

5. Andrei, G; Eur J Clin Microbiol Infect Dis 1995, 14, 318 MEDLINE.

6. Pharmhuy C, Stathoulopoulou, F.; Sandouk, P.; Scherrmann, J.M; Palombo, S.; Girre, C. Rapid determnation of valacyclovir and acyclovir in human biological fluids by high performance liquid chromatography using isocratic elution. J.Chromatogr. B 1999, 732, 47-53. 
7. Ayhan Savaser, Cansel Ozkan K, Yalcin Ozkan, Bengi Uslu and Sibel Ozkan.A, J.Liq.Chromatogr. Related tech.2003, 26, 1755-1767.

8 Chen, Yu, Yaowu Fenxi Zazhi Determination of famciclovir by HPLC, 2000, 20(3), 180-181.

9 Huang, Zongyu; Jin, Ou Yaowu Fenxi Zazhi determination of impurities in Famciclovir by high performance capillary electrophoresis .2000, 20(2), 111-113. 


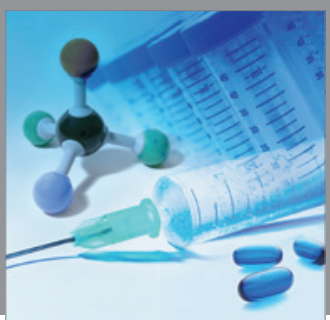

International Journal of

Medicinal Chemistry

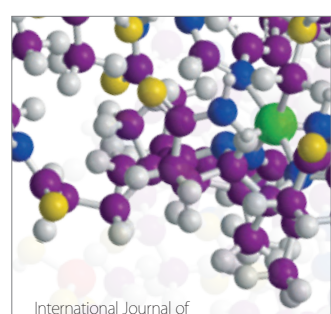

Carbohydrate Chemistry

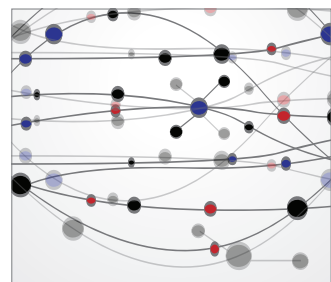

The Scientific World Journal
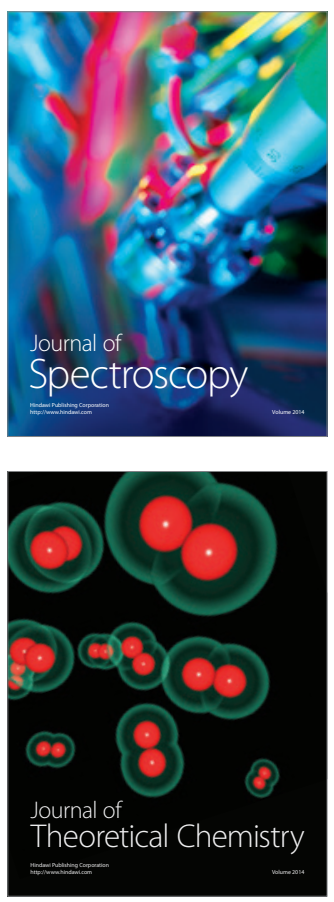
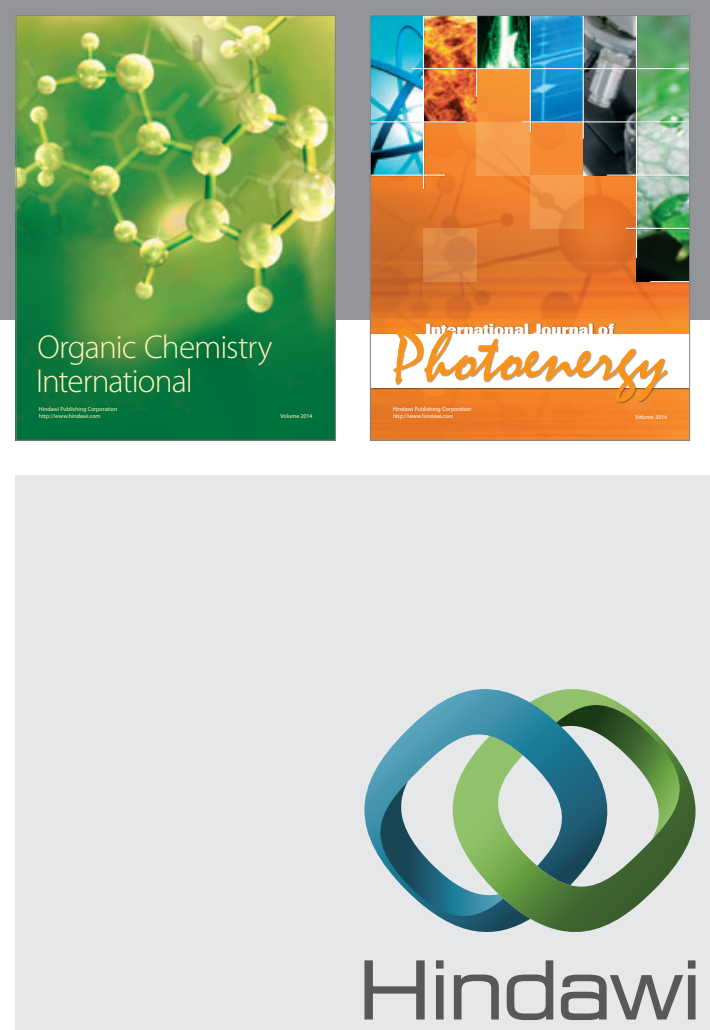

Submit your manuscripts at

http://www.hindawi.com
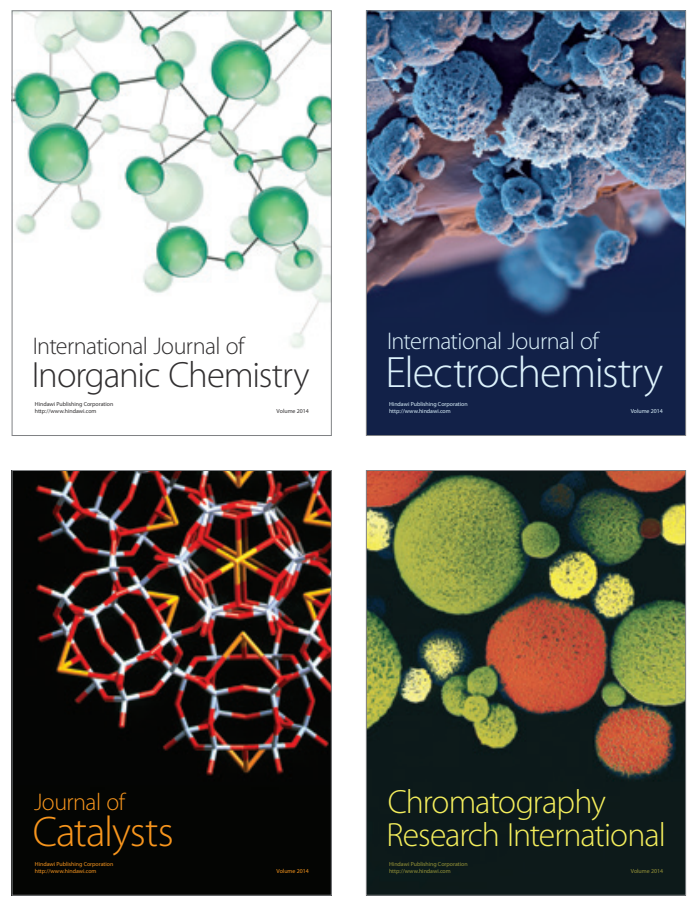
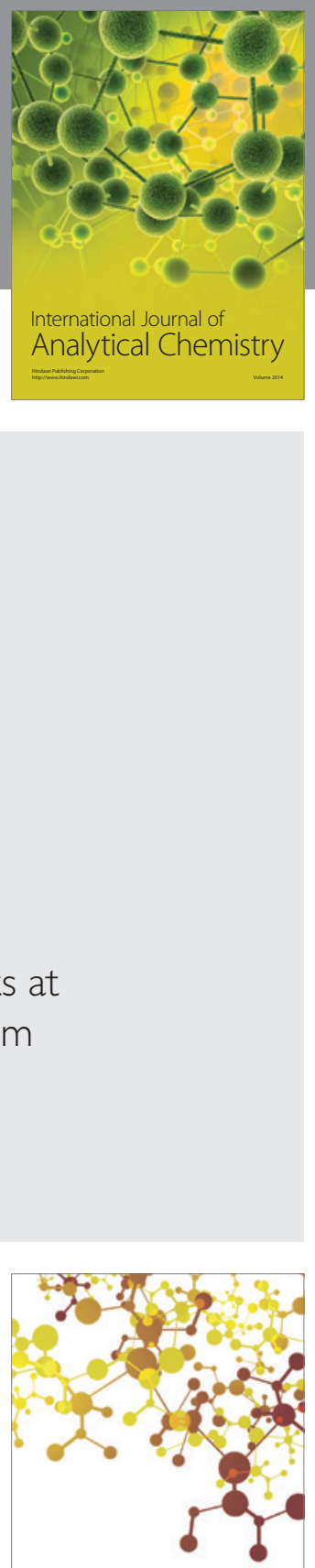

Journal of

Applied Chemistry
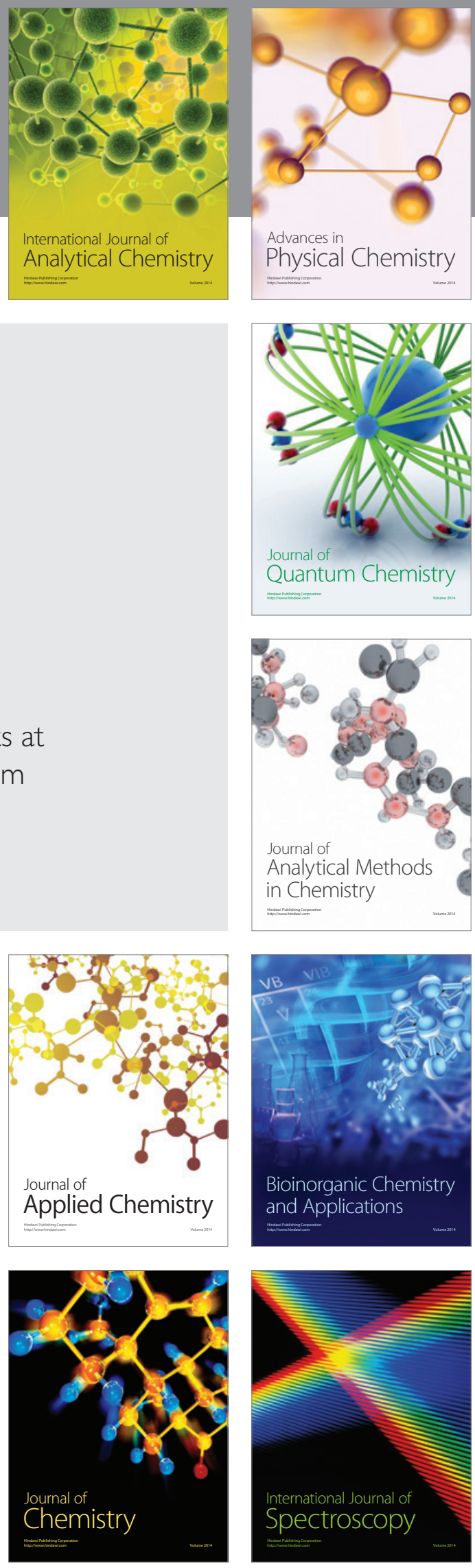